\title{
The danger of Dieselgate: how Volkswagen's diesel scandal critically damaged the wider market
}

In 2014, emissions violations were discovered in Volkswagen diesel vehicles. The research was conducted initially by a range of bodies, including a team at the West Virginia University, financed by the International Council on Clean Transportation. The results confirmed suspicions by other carmakers, such as General Motors, who were unable to replicate the results claimed by Volkswagen for their diesel engines. In 2015, these initial results were corroborated by the US EPA and the California Air Resource Board, and the scandal became global. It had been found that Volkswagen engineers had fitted cheat software that allowed the vehicles to run within the strict boundaries of Californian regulations for nitrogen oxide emissions during tests, but when run in the real world, the engine emissions were significantly higher. The furore was greater in the USA, but the ramifications for Volkswagen were felt around the globe. Importantly, the issue for the USA was the potential damage done to the diesel engine industry.

The fast-pace and global nature of communication and news means that the fallout of corporate scandals is larger, faster, and much harder to mitigate against. The rise of consumer groups and the ubiquitous use of social media to highlight and criticize corporate issues by users means that such scandals are no longer able to be kept within the scope of investors and industry figures. As such, corporations involved with scandals are penalized quickly and harshly. These consequences are also felt amongst the other supply organizations that are associated with the scandal. In the case of the Volkswagen scandal, other car marques from the Volkswagen Group, as well as associated German brands such as Bosch were adversely affected. Critically, consumers also questioned the environmental viability of diesel throughout the automotive industry.

There are considerable knock-on effects to scandals in such large organizations. Their requirements for suppliers to enable rapid and huge expansion in particular business areas (such as Volkswagen's desire to become the world's largest automotive manufacturer) mean that any market destruction can wipe out these now reliant smaller organizations. The consequences of the scandal reportedly cost those associated with Volkswagen a combined US $\$ 6.44$ billion. The effects of corporate scandals on organizations that were not complicit leads Nunes and Park (2017) to conceptualize the "inertial effect", leading to the research question:

$R Q 1$. Is the disclosure of an environmental fraud capable of triggering an inertial effect on other companies?

\section{Measuring the effect of corporate scandals}

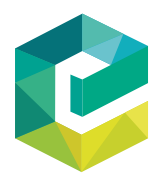

Annals in Social Responsibility Vol. 3 No. 1, 2017 pp. $68-69$

(C) Emerald Publishing Limited 2056-3515 DOI 10.1108/ASR-10-2017-0010
Corporate scandals refer to the disclosure of any information that damages or negatively impacts a firm. They are particularly damaging when the disclosed information reveals the internal recognition of a problem, and subsequent attempts to hide or mitigate the issue. In the current global climate, those scandals that have significant environmental or humanitarian effects are often seen as causing the greatest amounts of damage and disruption to the associated industry. The term "inertial effect" refers to the ability for a corporate scandal to spread outwards from the organization in which it originates to associated organizations and suppliers. Efficient market hypothesis proposes that any update of relevant information on an organization causes an immediate and correlated 
adjustment to its market value. Such a system should nullify any ability for investors to profit from any discrepancy between stock prices and their due value. The event study methodology is able to compare the actual returns of an organization to those that would be considered typical. Any difference here is labeled abnormal, and is considered over a period of time called the event window.

The inertial effect of the Volkswagen scandal can be considered, therefore, by the analysis of seven industry-level companies and 26 supply chain-level companies, using the NYSE, NASDAQ, and AMEX as reference points for market and stock value. The results show that two industry level and three supply chain-level companies lost significant market value as a result of the scandal, proving the inertial effect of Volkswagen's actions. The seven companies most affected all have diesel-powered products in their portfolios. As such, Dieselgate can be seen to have adversely affected the whole diesel industry, with the most significant damage occurring in the supply chain level. Here, losses can be totalled at US $\$ 4.26$ billion, compared to US $\$ 1.19$ billion for those companies at the industry level.

The research question of Nunes and Park (2017) can therefore be confirmed. Most profoundly, the unequal distribution of value loss between industrial and supply chain-level companies suggests the largest impact is on those companies whose value is based upon expected or potential future transactions with the scandal-hit company. As such, supply chain companies bear the greatest burden after the company where the scandal originates. In this case, Volkswagen lost value due to a loss of sales, cost of recalling vehicles, penalties, and the loss of potential merger and takeover options. Other industry-level companies lost value due to the damage done to the diesel market. Supply chain companies lost value due to aligning themselves both to the diesel market and to Volkswagen, due to its attempts to grow in the USA and sell one million vehicles a year.

\section{Comment}

The review is based on "Caught red-handed: the cost of the Volkswagen Dieselgate" by Mauro Fracarolli Nunes and Camila Lee Park, published in the Journal of Global Responsibility.

\section{James Andrew Robertson}

\section{Reference}

Nunes, M.F. and Park, C.L. (2017), “Caught red-handed: the cost of the Volkswagen Dieselgate”, Journal of Global Responsibility, Vol. 7 No. 2, pp. 288-302.
The danger of Dieselgate 